\title{
PSYCHE
}

VOL. XXXIV.

JUNE-AUGUST, 1927.

Nos. 3-4

\section{A STUDY OF THE MALE ABDOMINAL APPENDAGES OF THE NAIS-GROUP OF APANTESIS WALKER. (LEPIDOPTERA ARCTIIDÆ)}

\author{
By Elmer T. Learned, M. D. \\ Fall River, Mass.
}

The genus Apantesis is composed of moths well known for their variability, a character especially marked in the four forms: nais Drury, vittata Fabricius, radians Walker, and phalerata Harris. The close relationship of these moths suggested that it would be interesting to examine the male abdominal appendages in a series, to see to what extent these organs vary, and whether constant structural differences exist between the forms as separated by superficial characters. Before considering the genitalia I propose to summarize briefly what is now known about these moths.

The range of variation in these insects is so wide that it is impossible to give a description which will always serve to distinguish one form from all its allies. Each tends toward a certain characteristic type, however, and in spite of the similarity in markings the moths are readily separable into the four forms. With a knowledge of the habitus of each form and appreciation of the factors which are apt to vary it in one or another direction, only old or worn specimens and occasional extreme variations should cause confusion.

Nais includes specimens predominantly yellow in color, comparatively robust thorax with rough vestiture, the collar most often immaculate, the pattern of the forewings usually complete or nearly so, always with black costal edge; the hind 
wings sometimes tinged with red, the black spots discreet, rarely fused or absent.

In vittata the pattern of the fore-wings usually lacks the $\mathrm{W}$ mark, and the costa is pale. A character sometimes useful is a tendency to a more evenly rounded outer margin of the forewings, giving them a broad and stumpy appearance. The hindwings are usually red, sometimes yellow, the black spots often fused. The dorsum of the abdomen may or may not be broadly black.

A brood of vittata which I reared recently thru two generations appears to be a mutation. All the moths of the first generation had a black costal margin on the fore-wing, instead of the pale one usual to vittata, and the male appendages showed a constant difference from the normal form thruout both generations.

Radians is closest to phalerata in appearance, but the pattern of the fore-wings is usually abbreviated as in vittata, with pale costa. The hind-wings are typically yellow tinged with red, exactly as in phalerata, and similarly the red may be entirely lacking, or may predominate. I include under radians the form floridana Cassino, and regard this name as a synonym. The female floridana does not differ from the form which has always been regarded as radians, and the male agrees with the description and figures of the male which Seifert first associated with radians by breeding.

Phalerata is the most protean of the four forms. While in most cases easily recognized, its variations may almost exactly resemble any of the other forms. The pattern of the fore-wings is usually complete, but is often more or less abbreviated and the costa may be either black or pale. The fore-wings tend to be comparatively narrow, particularly as compared to vittata, with the outer border more oblique with well marked apex. The hind-wings vary from the typical yellowish tinged with pink at the inner margin, to pale yellow or red. The abdomen is more frequently tinged with reddish on the sides than in the other forms.

There is a form of phalerata, apparently common in Florida, and which I also have from Alabama and Arkansas, which has 
the pattern of the fore-wings complete, and the hind-wings immaculate (except for black along the costa) and varying from the bright pinkish to pale yellow in color. This form is particularly mentioned because of its resemblance to both nais and radians.

The females of three of the four forms are even more similar than the males. Nais is distinguished from vittata by its black costal margin, while vittata and radians differ only in the extent of the markings of the fore-wing, and grade into each other. The female phalerata stands apart with a more complete pattern on the fore-wings and a broken border on secondaries. I find, moreover, a small but constant difference from the other three forms in the female genitalia.

Life histories of nais and radians have been published by Seifert, and of phalerata by Gibson. So far as I have been able to discover, no life history of vittata has been published; brief descriptions of the adult larva occur in papers by Dyar, and by Gibson. A few descriptions of larvæ were published by earlier writers, but are too generalized to be of much value, for the larvæ of this group are so similar that descriptions must be minute to be of use for comparisons. The larvæ are as variable as the moths, and in the same brood may vary in the presence or absence of a dorsal line or other marking, in their color, and in the color of the lateral setæ. Gibson could see no difference between the larvæ of nais and phalerata. Other descriptions, however, imply that the larvæ of all the forms differ. They are probably not yet well enough known to permit definite conclusions in regard to them.

The similarity of the moths of the nais-group has caused some difference of opinion as to whether they are all forms of one species or four distinct species. I have found nothing in the literature to show that one form has ever been bred from another, aside from statements unsupported by evidence, and one instance where it appears that mistaken identification has caused confusion. On the other hand, reports of observers with experience of several broods indicate that the forms breed true. Seifert reared a number of broods of nais and experimented with temperature effects on the pupæ. He also reared radians thru two generations, and attempted to mate females by exposing 
them in localities about New York where vittata was known to occur, but without success. This appears significant, but the possible effect of climatic difference on fertility must be considered. Marchand concluded that nais, vittata and phalerata were distinct species; he reared several broods of nais and phalerata which always bred true. His attempt to cross these moths was unsuccessful as would be expected from the genitalic differences, which he notes.

It is not necessary to assume that interbreeding must occur to explain occasional extraordinary resemblances between these forms. Variability is inherent in living organisms, and since the characters which vary in these moths are the same in all, any departure of a form from its normal mean makes it approaach one of the other forms. Also, in closely related forms apparently recently differentiated the occurrence of atavism may explain some of the intergrading individuals.

There is nothing in the literature on the genitalia of Apantesis with the exception of a brief paper by Dyar in which he figures the claspers and tegumen of nais, vittata, and phalerata. Dyar concluded that phalerata was a good species, but later placed it as a variety of vittata in his catalog.

The species of Apantesis as a whole show a wide range in the form of the male abdominal appendages. The moths of the nais group differ in common from the other species which I have examined. The ædoeagus in other species than those of the nais group is evenly and moderately chitinized thruout, except for occasional thickening near the orifice, and is unarmed. In the nais group this organ has a part of the circumference of the distal half thickened and heavily chitinized, and armed with one or more stout spines. I find no name in the literature which seems to apply to this localized area of thickened chitin in the ædoeagus, and will refer to it as the callum ("thickened skin"). In this thickening and armature this group resembles other Arctiidæ, in some of which the ædoeagal armature is highly developed.

The claspers are inwardly concave, roughly quadrilateral in shape, with an arm arising from the upper edge and projecting inwardly toward that of the opposite clasp. The distal portion of the clasper is composed of two distinct layers of chitin; the 
free edge of the inner layer is sharply defined. The lower border of the clasp is excavated near its middle, proximal to which it curves inward. This inward curve becomes more marked in prepared specimens, and as it is impossible to flatten the clasp without distorting it, the drawings show this part of the lower edge upturned.

The uncus consists of a broad basal part which joints the tegumen, and distally becomes spear-shaped as seen from above, beak-like laterally. There is a deep groove where the broad base of the uncus joins the tegumen, which is hardly noticeable from above. The ventral half of the tegumen shows no characteristic differences in the group, except that it is narrower and more pointed in radians and phalerata. The juxta in the naisgroup as seen from below appears cone-shaped, and projects from the manica. In other species of the genus it consists of a thickening of the manica which remains closely apprest to the ædoeagus.

The organs are so curved, especially the claspers that great care is necessary in making comparisons, for a slight difference in orientation will make a great difference in the apparent shape of the organ. For this reason the usual balsam mounts were found unsatisfactory in this study, and after preparing the genitalia in the usual way and studying the structures as a whole the componene organs were dissected apart and compared unmounted. Before beginning the study of the genitalia the specimens were sorted into the different groups on superficial characters. The genitalia of seventeen specimens of nais were examined, twentyone of vittata, (besides seventeen of the aberrant brood), eight of radians, (including floridana), and fifty of phalerata. All the radians were from Florida; the other series included moths from various localities. Each series included specimens showing wide variations in maculation.

A. nais (Figs. 1-7). The usual form of the clasper is shown in Fig. 2. Variations occur in the relative length and width of the part, the length of the rounded apex, and the degree of curvature of the posterior (distal) edge. Fig. 3 shows a clasper in which all these variations appear. In all the species variations occur in the size and shape of the costal arm, the extent of the 
the lower border, and are of no significance. The basal part of the uncus tends to be a little rounded at the sides, but this varies, as does its width. Fig. 5 shows an average specimen; in others the spear-head may be shorter and broader, or it may be narrower. The juxta resembles a bisected cone, the flat surface against the manica, and varies much in length and breadth; in most specimens it is evenly tapered to a rounded point, but in two the end is broad and blunt. Figs. 6 and 7 illustrate two extremes.

The ædœagus is similar in shape to vittata and radians, consisting of an irregular chitinous tube with a slight double curve in the sagittal plane, the duct entering thru its dorsal surface just distal to the base. Size and details of shape and curvature are subject to individual variation in all the species. On the right lower lateral and extending partly onto the ventral aspect of the distal portion is the area of heavy chitinization which I have called the callum. Distally it is produced into a stout, hook-like spine, which points at right angles to the axis of the ædoeagus, and the whole hook-like structure is sharply bent laterally. The callum tapers proximally, and the proximal part becomes twisted nearly at right angles to the distal portion due to the upturning of the lower edge, and is often curved toward the dorsum. This peculiarity is particularly well marked in the specimen selected for Fig. 1. The distal edge of the callum forms part of the boundary of the orifice, and the vesica is attached to it; elsewhere the callum blends into the normal chitin. Wide variations are found in the length and width of the callum, and in the size and shape of the spine; in all the specimens examined, however, the proximal portion showed the characteristic twist. One aberration was found with small callum and a bifurcate spine (Fig. 4). Nais showed a much smaller range of variation in the genitalia than the next species.

A. vittata (Figs. 8-16) bears an exceedingly close resemblance to nais in the genital structures. The variations in claspers, uncus, and juxta in each species grade into each other so that it is often impossible to tell from one organ alone to which species it belongs. The claspers of vittata vary along the same lines as those of nais, but the range of variation is greater. The average form of clasp is shown by Fig. 13. Its close similarity to that of 
nais is seen by comparing Fig. 2. A more definite angle at the junction of the posterior and upper margins in vittata is the only difference, (the shape of the costal arm and of the lower border is of no importance) and sometimes serves to distinguish them, but is not constant. The specimen in Fig. 9 (which happens to be from a large moth) has as evenly curved a posterior edge as has nais. The other extreme is shown in the clasp with flattened, oblique, posterior margin (Fig. 16). The uncus is similar to that of nais and varies to the same extent. The basal part tends to be less rounded in vittata with the sides more sloping, but Figs. 5 and 12 were selected to show the different forms, and are not intended to imply a constant, specific difference. The usual form of the juxta is shown in Fig. 10. It varies in length and in three specimens was as long as in nais, (Fig. 11).

The ædoeagus is similar to nais, but thruout the series a constant difference was found in the callum. It differs from nais in the proximal end, which flattens out and blends into the normal chitin, while in nais this end becomes twisted. There is more variation in vittata in the shape of the spine, several variations of which are shown (Figs. 8, 14, 15); one specimen was found with a long, bifurcated spine. Fig. 15 shows the closest approach to nais found in the series, in the short, broad callum (the shape of the spine is not important) but the proximal end shows the difference noted.

Figs. 17-21 are from specimens of the aberrant brood of vittata mentioned above. The same peculiarities were found in two generations. The claspers are not distinctive. Tho relatively long and narrow, with an unusually broad arm, they are probably within the range of variation of vittata. The uncus is remarkably different, having the spear point nearly twice as long as in any other form, and with prominent rounded "shoulders" on the basal part. It was the same in all the specimens examined. The juxta has a broad, blunt end. The ædoeagus differs from the normal vittata in the absence of the lateral bend of the distal portion of the callum, and has two diverging, nearly equal spines. Two specimens were exceptional in having but one spine, thus resembling normal vittata. The occurrence of a double or bifurcate spine as an aberration 
in both nais and vittata, is interesting as showing a tendency which has become fixt in the next two forms.

In radians (Figs. 22-28) the claspers show a strong tendency to a very oblique posterior margin (Fig. 23.) This resembles an extreme form of vittata (Fig. 16), but the obliquity is greater in radians. One specimen, however, (Fig. 28) is similar to both nais and vittata. The uncus does not differ much, if at all, from nais and vittata. The slight difference is found in a shorter and broader spear-head. The juxta has a flat, broad tip, and resembles that of the aberrant form of vittata, a form also found in nais. The ædoeagus shows a characteristic peculiarity in having multiple spines-two specimens had four spines (Fig. 22), five specimens had three spines (Fig. 27), and one had but two, (Fig. 26). The callum resembles that of vittata, but the distal part is broader, and lacks the lateral bend, being drawn out into a strong spine; above this main spine are smaller ones, diminishing in size dorsally. In the specimen with only two spines, they are nearly equal, the second one abnormal in being directed posteriorly.

A. phalerata (Figs. 29-38) differs remarkably from other members of the group, and is unique in the form of the claspers and ædoeagus. The clasper is of unusually large size and exceeds that of the largest species of the genus, A. virgo. Individual variations are slight, and consist in differences in length and shape of the terminal projection, and in the degree of angulation of the upper edge; Fig. 32 shows an extreme form in which one angle is completely flattened out. A slight asymetry is sometimes found between the clasps of opposite sides. The uncus differs from the other species in the longer and narrower spearhead, with evenly curved edge, and the basal portion is also relatively long and narrow. The juxta, seen from below (Fig. 33 ), is flattened at the base while the distal part is comprest laterally more narrowly than in the other moths, so that it forms a keel-like projection. There is little individual variation in either uncus or juxta.

The ædoeagus is distinctive. The thick, heavily chitinized area covers nearly the whole of the right side of the distal half, curving onto the ventral side and over the distal end, forming a 
sort of three sided investment. At its apical angle it is produced into two slightly diverging stout conical spines; proximally it tapers into a narrow ridge. In the figure a large portion of the callum is obscured, being overlapped by other parts. The ædoeagus of phalerata is unique not only in external structure, but the vesica also differs in form from that of the other moths of the group. The ædoeagus was found to be variable in regard to the terminal spines, about one out of every four specimens examined showing some departure from the normal evenly bifid structure; such variation ranged from a slight irregularity in size of the spines to complete absence of a spine on one hand, and on the other the addition of a third spine; the presence of a third spine appears to be due to the bifurcation of one of the existing spines, rather than the production of a new one. Several such aberrations are shown in Figs. 35-38.

The moths used in this study were sorted into four groups before beginning the study of the genitalia and the structural differences were found to correspond with the separation on superficial characters, with two exceptions. One specimen was included under phalerata which structurally proved to be radians, and a specimen of vittata was also found under phalerata. Each of these specimens was atypical in maculation and represented a borderline variation; the genital structures, however, were perfectly typical. It is worth noting that while phalerata is the most protean of the forms and most apt to cause confusion by the similarity of its variations to the other forms, it differs the most in structure. In making determinations it is necessary only to remove a few hairs to expose the long narrow terminal projection of the clasper characteristic of phalerata. With phalerata eliminated, of the remaining three forms nais is recognized by its black costa, while vittata and radians usually differ in the coloration of the hind wings.

Nais and vittata are found to be very similar structurally but a constant tho slight difference occurs in the ædoeagus. Radians differs from them in the multiple spines of the ædoeagus, and for the most part the claspers are characteristic tho they may resemble vittata. Study of a larger series of radians would be desirable. Phalerata shows a surprising degree of divergence from 
its allies, all the genital structures being unique, including the vesica. The variations of the genitalia which occurred within each form were found to be independent of variations in maculation, nor did they bear any relation to locality.

No one factor, structural or otherwise, can determine a species, and more knowledge of the early stages, bred thru more than one generation, is essential to a thoro knowledge of any form. As our knowledge stands at present, however, I believe the evidence indicates that all of the forms are species. We have four forms readily separable on superficial characters and with corresponding structural differences, no one of which is known to have been bred from the other. It seems more logical to regard such forms as distinct until proved otherwise, than to lump three of them under one species as at present.

\section{Bibliography}

The following bibliography includes only those titles subsequent to 1890. References prior to that date will be found in J. B. Smith's "Preliminary Catalog of the Arctiidæ" (Can. Ent. 1889, XXI, p. 169)

Barnes \& McDunnough, 1912, Can. Ent. xliv, 189.

$$
\text { 1917, Check-List. }
$$

Beutenmuller, W. 1898, Bul. Am. Mus. Nat. Hist. x, 381.

Cassino, S. E. 1918, Lepidopterist, ii, 2.

Dyar, H. G. 1893, Psyche, vi, 479.

1900, Jour. N. Y. Ent. Soc. viii, 37.

1902, Cat. N. A. Lep.

(Engel), 1903, Ent. News, vix, 307.

Gibson, A. 1900 , Can. Ent. xxxii, 369.

1902, Can. Ent. xxxiv, 50.

1903, Can. Ent. xxxv, 153.

1905, Can. Ent. xxxvii, 347.

Hampson, G. F. 1901 Cap. Lep. Phal. Brit. Mus. iii, 410.

Cat. Lep. Phal., Supplement ii.

Holland, W. J. 1904, Moth Book, 132.

Marchand, W. 1917, Psyche, xxiv, 59.

Neumoegan \& Dyar, 1893, Ent. News, iv, 213. 1894, Jour. N. Y. Ent. Soc. ii, 14.

Seifert, O. 1902, Jour. N. Y. Ent. Soc. x, 4; 88.

Seitz, A. 1919, Macrolepidoptera, vi, 305.

Smith, J. B. 1892, Can. Ent. xxiv, 133.

1909, Rept. Ins. N. J., 441.

(Smith, J. B.) 1897, Ent. News, viii, 114.

Stretch, R. 1906, Jour. N. Y. Ent. Soc. xiv, 120. 


\section{Explanation of Plates IV and V.}

The left clasper is shown, as seen from its inner surface. The uncus, attached to the dorsal half of the tegumen, is seen from above; the uncus is more heavily outlined. The juxta is seen from below. The right lateral aspect of the sedoeagus is shown, the dorsum to the right. Drawings were made with camera lucida; all are to the same scale.

Figs. 1-7, A. nais.

1, ædœagus. 2, clasper. 3, clasper, variation.

4, ædœagus, aberration. 5, uncus. 6-7 juxta, variations.

Figs. 8-21. A. vittata.

$8,14,15$, normal forms of ædœagus. 10, 11, juxta. 12 , uncus. 13 , clasper. 9,16 claspers, variations.

17,21 , ædœagus of aberrant form. 18, 19, 20, clasper, juxta and uncus of aberrant form.

Figs. 22-28, $A$. radians.

$22,26,27$, forms of ædœagus. 23,28 , claspers.

24 , uncus. 25 , juxta.

Figs. 29-38, A. phalerata.

29 , ædœagus. 30 , normal clasper. 31 , uncus.

32 , clasper, variation. 33, juxta. 34, lateral view of juxta. 35-38, variations of ædœagus, (ventral aspect). 


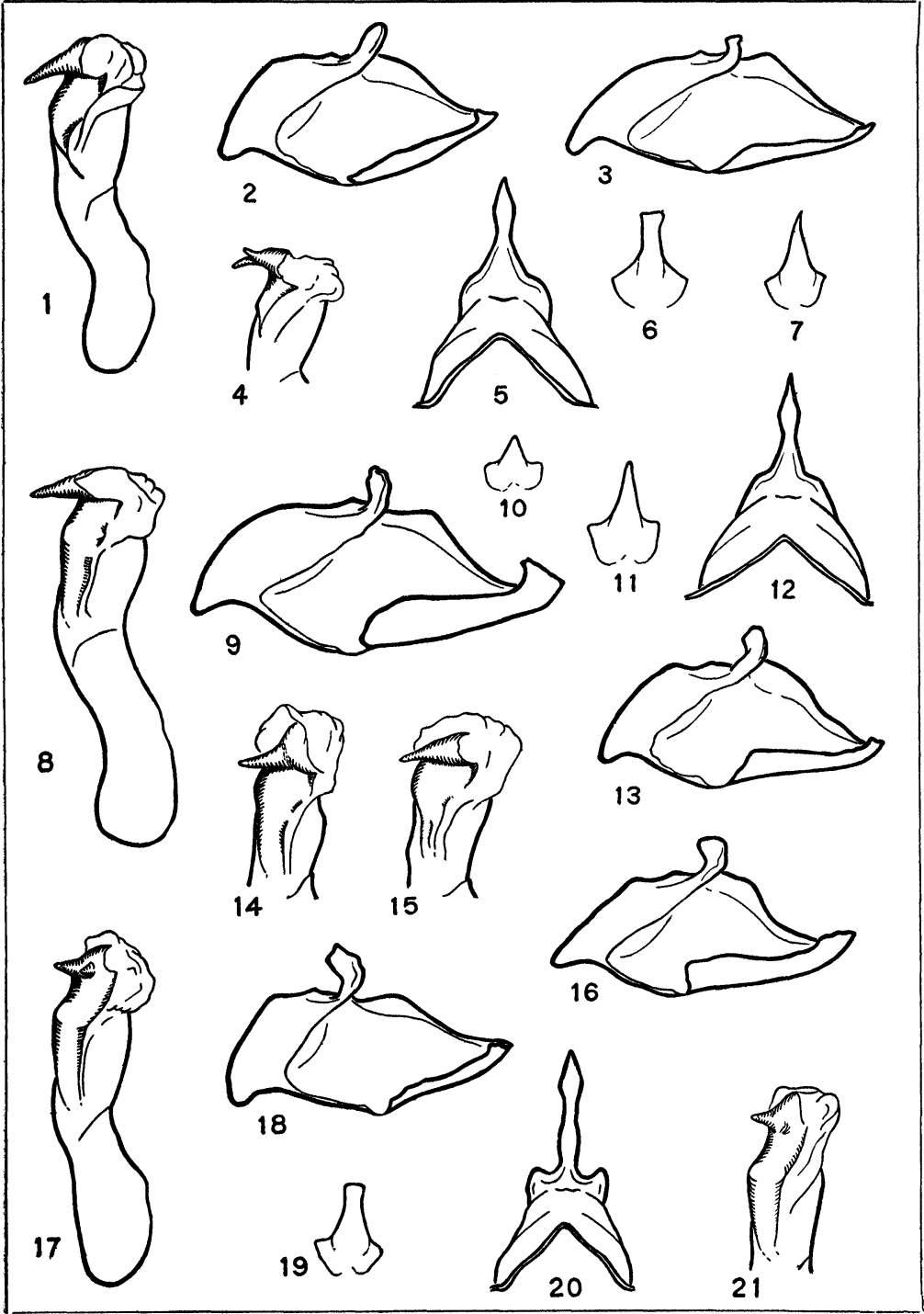

LEARNED-NAIS - GROUP OF APANTESIS 


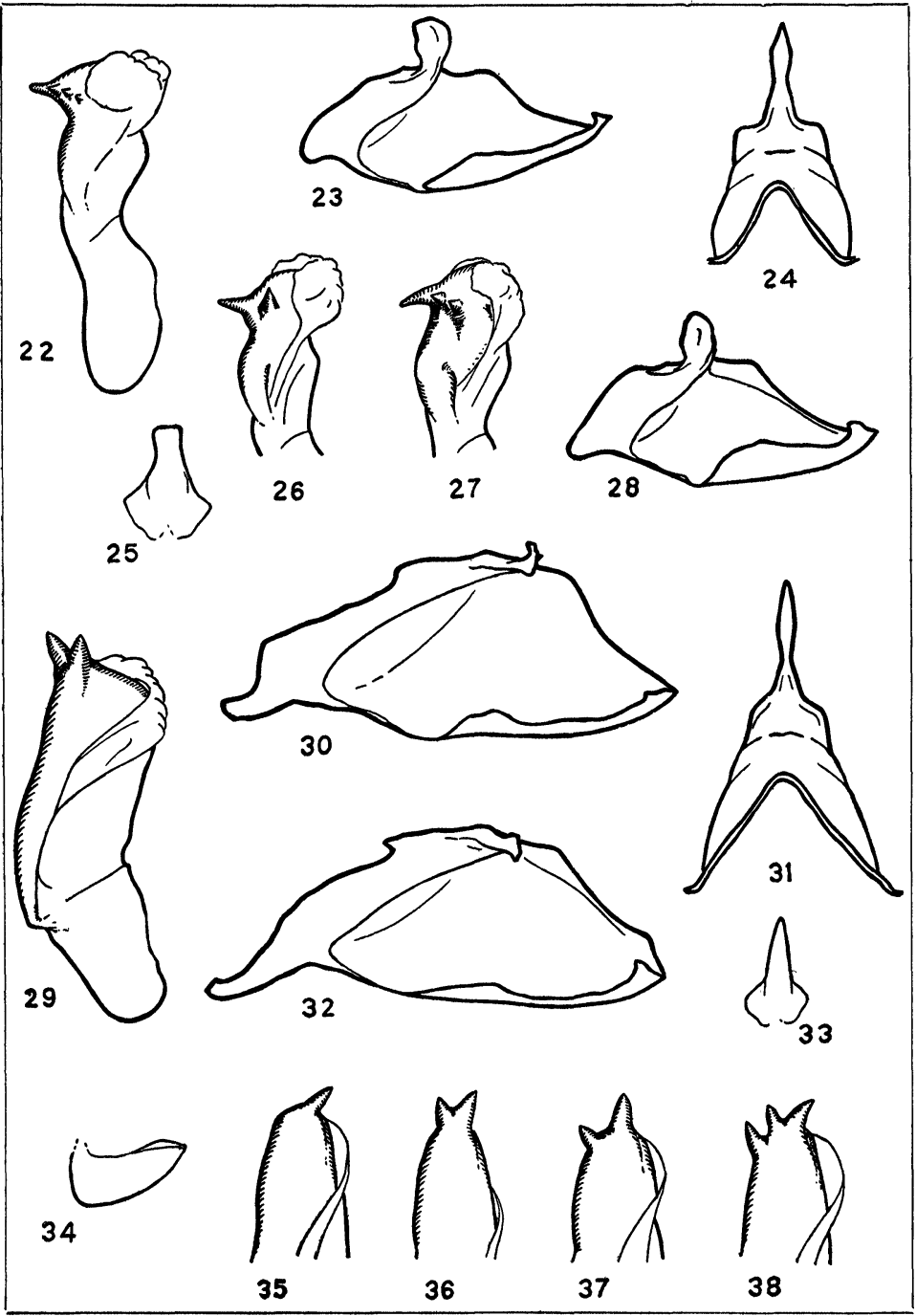

LEARNED-NAIS - GROUP OF APANTESIS 

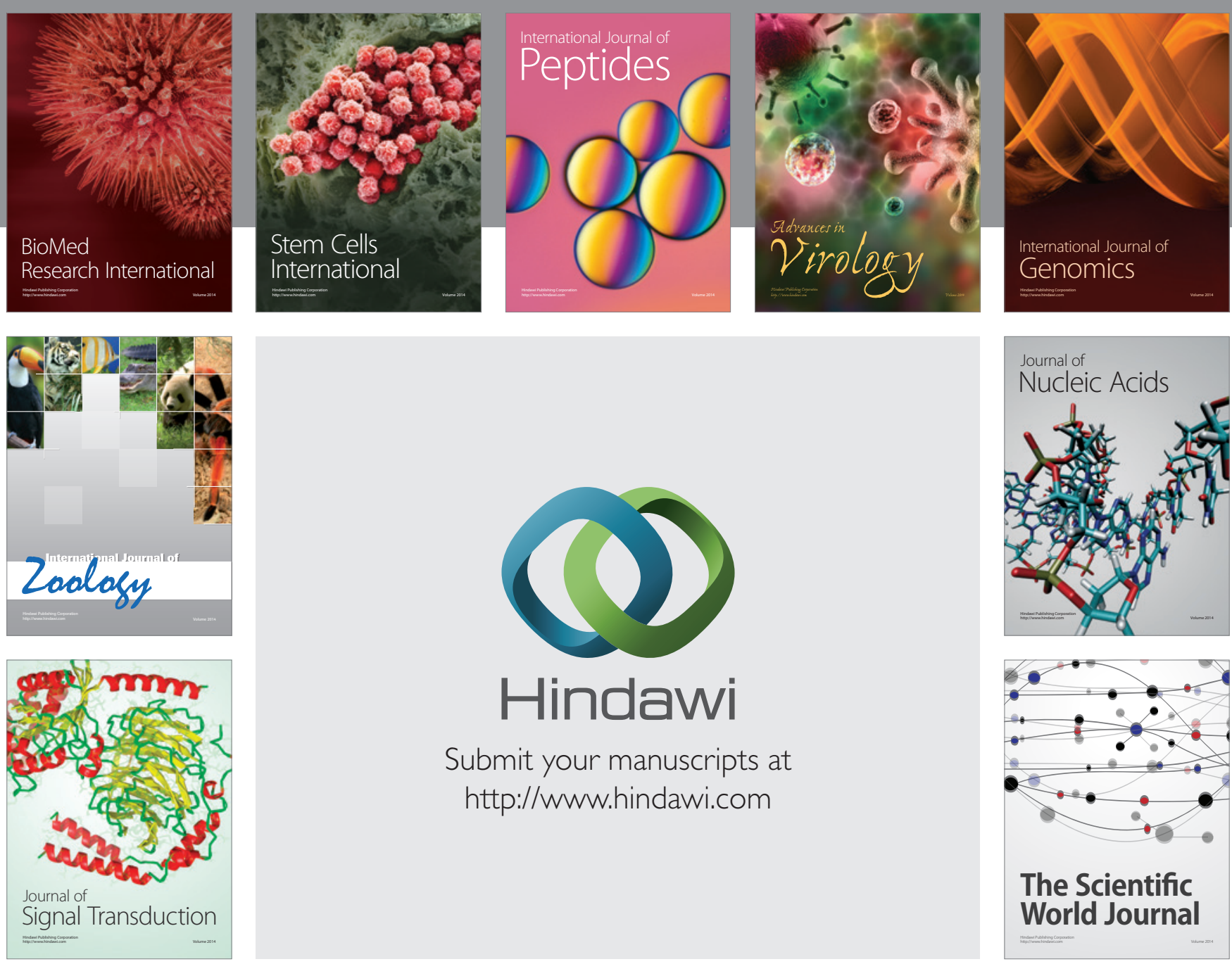

Submit your manuscripts at

http://www.hindawi.com
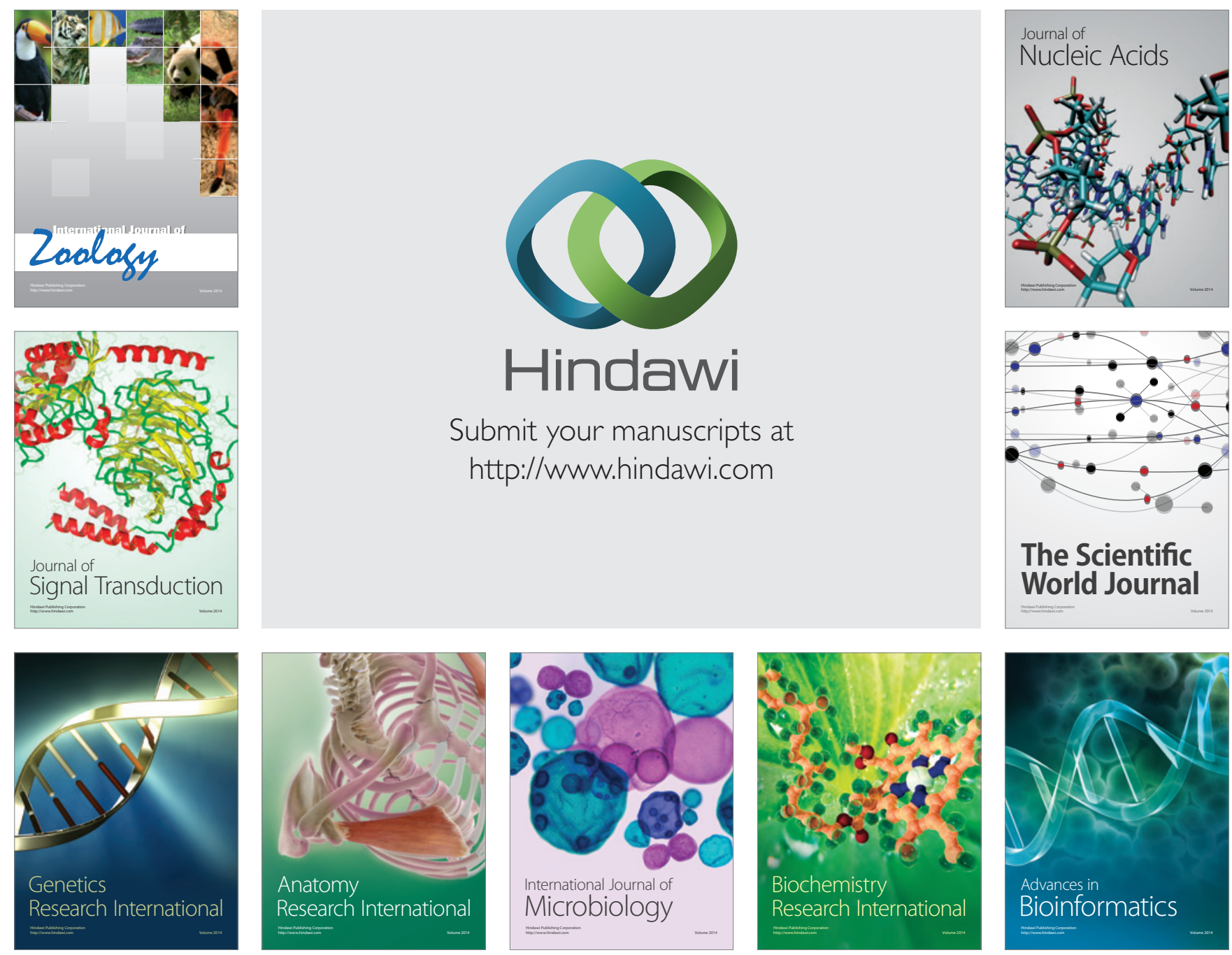

The Scientific World Journal
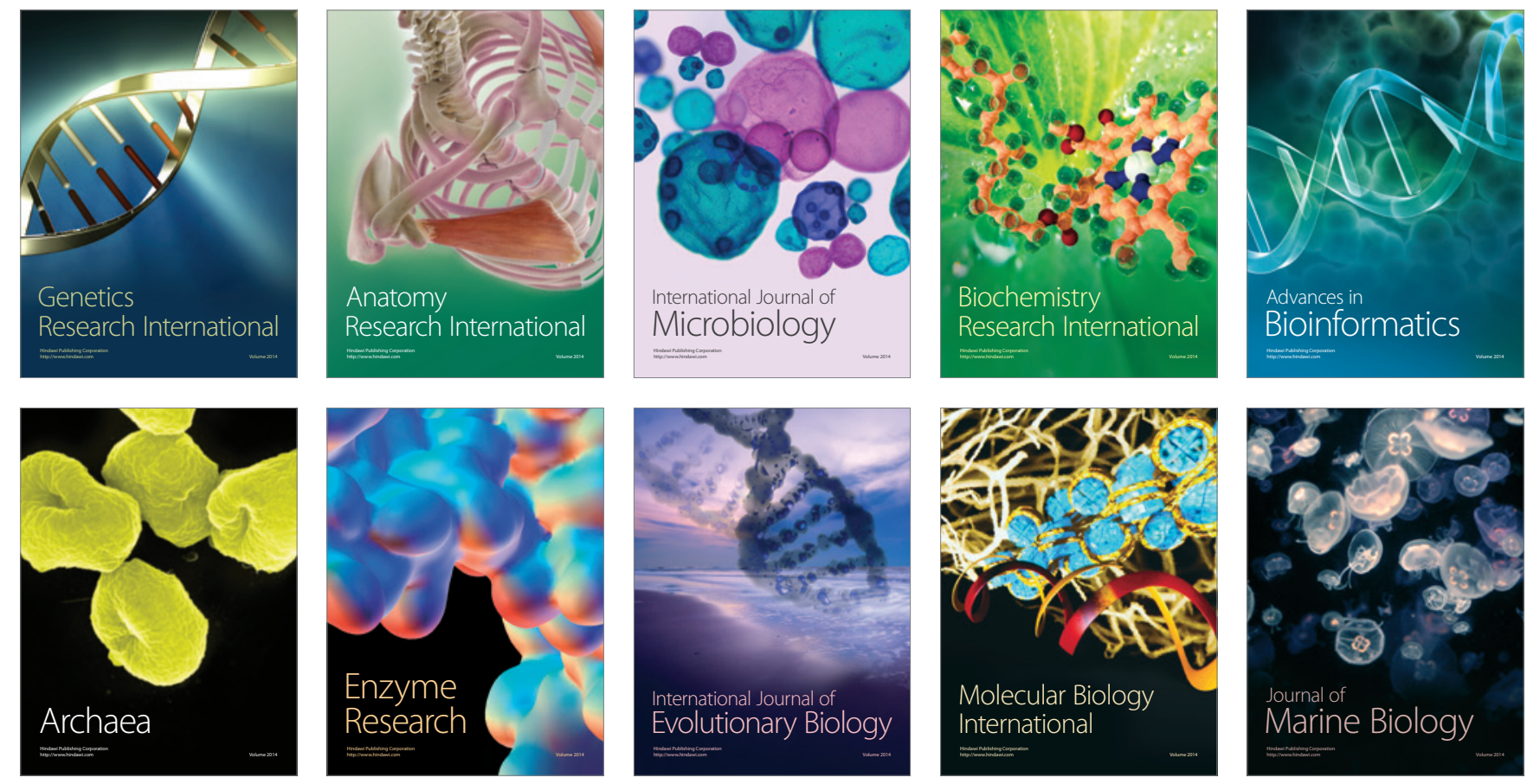